www.jmscr.igmpublication.org

Impact Factor 5.84

Index Copernicus Value: 71.58

ISSN (e)-2347-176x ISSN (p) 2455-0450

crossref DOI: _https://dx.doi.org/10.18535/jmscr/v5i11.01

Journal Of Medical Science And Clinical Research

\title{
Characterization, Estimation and Evaluation of Antifungal Activity of Lipids Isolated from Iraqi Capparis spinosa Leaves Buds
}

\author{
Authors \\ Abbas Dawwas Matter Al-Maliki ${ }^{1}$, Majda Ismaeel Abd- Al-Majeed ${ }^{* 2}$ \\ Makarem Abdul Razzak Jassem Al-Abdal ${ }^{3}$, Ban Abdul- Majeed Esmaeel ${ }^{4}$ \\ ${ }^{1}$ Department of Chemistry, College of Education for Pure Sciences, University of Basrah, Basrah, Iraq \\ ${ }^{2,3}$ Department of Biology, College of Education for Pure Sciences, University of Basrah, Basrah, Iraq \\ ${ }^{4} \mathrm{Abu}$ AI-Khaseeb Education-Basrah, Education Directorate-Basrah-Iraq \\ Corresponding Author \\ Majda Ismaeel Abd- Al-Majeed* \\ Email:imajda@yahoo.com
}

\begin{abstract}
The current work was carried out to isolate, characterize, estimate and evaluate the biochemical activity of lipids from Iraqi Capparis spinosa L. leaves buds against three pathogenic fungi. The active isolated lipids were identified by using Gas chromatography- mass spectroscopy (GC-MS) technique. The concentration of $0.10,0.15,0.20,0.25$ and $0.30 \mathrm{mg} / \mathrm{ml}$ recorded inhibition zone diameters equal to $10,17,16,17$ and $17 \mathrm{~mm}$ respectively against Aspergillus flavus fungus. Also the same concentrations showed inhibition zone diameters represented by 17,16,19,19 and $19 \mathrm{~mm}$ respectively against Rhizopus fungus whereas the concentrations of active lipids gave 40,37,35,25 and $25 \mathrm{~mm}$ respectively towards growth of Candida albicans fungus. Therefore the isolated active lipids of Capparis spinosa leaves buds can be used safely to treat various diseases caused by these pathogenic micro-organisms instead of antibiotics but this work demands further clinical and pharmaceutical studies.
\end{abstract}

Key words: Capparis spinosa, Active lipids, Pathogenic fungi, GC-MS technique, Active chemical groups.

\section{Introduction}

The medicinal importance of medical plants comes from their biochemical activity to treat the various diseases caused by different pathogenic micro organisms such as bacteria, fungi and parasites. These medicinal plants have many active chemical compounds as secondary metabolites resulting from secondary metabolism pathways and these compounds have various active functional groups in their chemical structures $^{[1,2]}$. The active chemical compounds existing in different parts of medicinal plants are phenolic compounds, flavonoids, tannins, alkaloids, glycosides, essential oils and steroids, so the presence of these secondary metabolites in plant give the medicinal and biochemical action of these plants to treat various diseases. The clinical microbiologists have some reasons to be interested in the subject of antimicrobial activity of active chemical compounds extracts of medicinal plants, the first reason is the medical importance of photochemical as drugs against biological action of micro-organisms then use of natural 
components to treat human diseases and the second is that these active compounds isolated from plants have no side effects ${ }^{[3,4]}$. Many various studies were achieved concerning the biochemical activity of active chemical metabolites as antibacterial, antifungal, antiparasitic, antitumor and anticancer agents also excellent results were gotten from effect of these chemicals against growth of different pathogens and cancer cells therefore the herbs and plants were considered as therapies and drugs to treat all infections and inflammation caused by these pathogenic micro$\operatorname{organisms}{ }^{[5,6]}$. Pathogenic fungi are various microorganisms live in different places such as human body, animals body, on surfaces of plant, on fruits, on meat and in air. They cause different infections and inflammation for human being, animals and plants so these biochemical effects of the pathogenic fungi lead to occurring many biochemical disorders in metabolism processes leading to happen various diseases. Many pathogenic fungi were isolated and identified by special microbiologist such as Rhizopus, Aspergillus flavus, Candida albicans and Aspergillus niger ${ }^{[7,8,9]}$. Rhizopus fungus belongs to zygomycetes fungi and it growth fast on foods media and this fungus is known as bread mold and this pathogenic microorganism caused the mold to vegetables and fruits called soft Rot disease. The ends of this fungus carries Aplanospores. Concerning Aspergillus, also it is one of plectomycetes fungi and it has cleistothecia containing Ascospores. This pathogenic fungus causes various diseases for respiratory system ${ }^{[10]}$. Candida albicans is of the fungi which belong to Ascomycota from the Hemiciasconmycetes species and this pathogenic fungus grows on culture media or in living tissues as spherical cells have buds have cream - white color and it lives naturally in digestive system, respiratory tracts and on $\operatorname{skin}^{[11,12]}$. This pathogenic fungus has the ability of transformation and conversion from an a shape to another one because outer and inner signal and this important biological process leads to make the fungus is pathogenic and cause the
Candidiasis disease ${ }^{[13]}$. Capparis spinosa L. is one of medicinal plants belong to Capparaceae family and it is an aromatic plant grows wild in dry places around Mediterranean basin. This plant has many various medical properties and uses to treat different diseases because it contains many active chemical compounds are abundant in its various parts as secondary metabolites such as phenolic compounds, flavonoides, tannins, essential oils, glycosides, alkaloids, terpenes and steroids ${ }^{[14,15]}$. The fruits and roots of Capparis spinosa are traditionally used to treat some diseases such as diarrhea and hemorrhoids and chemical aqueous methanolic, ethanolic, ethyl acetate extracts were used successfully against growth of pathogenic bacteria. Also the phenols and flavonoides isolated from their fruits and roots were used as antioxidant agents and the aqueous and ethanolic extracts of the roots of Capparis spinosa were used as antifungal chemical agents [16,17]. Many studies were achieved about Capparis spinosa L. include its different parts which were represented by roots, fruits, buds, seeds and leaves and the medicinal biochemical role of their active chemical compounds as antibacterial, antifungal, anticancer, antitumor and antioxidant ${ }^{(18,19,20)}$. The current study has focused on the antimicrobial activity of active lipids isolated from Capparis spinosa buds against three pathogenic fungi.

\section{Materials and Methods \\ Plant material}

Capparis spinosa L.(Capper) buds were gotten and collected from Abu- Al- Khaseeb district at Basrah governorate in Iraq. The plant was taxonomies in biology department at college of education for pure sciences in University of Basrah, cleaned by cold distilled water, dried in the shadow at room temperature, ground, powdered and kept in dark plastic containers until of use.

\section{Chemicals}

Pure chemical compounds were used in this research and they were represented by distilled water, hexane and phenyl methyl silox. 


\section{Pathogenic Fungi}

Three fungal strains are Aspergillus flavus, Rhizopus ssp. And Candida albicaus were isolated and identified by a microbiologist in microbiology laboratory in biology department at college of education for pure sciences at university of Basrah in Iraq.

\section{Culture media}

Sabouraud Dextrose Agar (SDA) was used to growth Candida albicans fungus and this medium was prepared by dissolving $56 \mathrm{gm}$ in $1000 \mathrm{ml}$ of distilled water ${ }^{(21)}$. Potato Dextrose Agar (PDA) was carried out to growth Aspergillus flavus and Rhizopus fungi and it was prepared by dissolving $39 \mathrm{gm}$ in $1000 \mathrm{ml}$ of distilled water ${ }^{(22)}$. Culture media were prepared according to procedure determining by manufacturing company represented by Hindi in India. Then the media were sterilized in the autoclave at $121^{\circ} \mathrm{C}$ under pressure equal to $15 \mathrm{p} /$ inch $^{2}$ for 15 minutes.

\section{Isolation of lipids from Capparis spinosa $\mathbf{L}$.} buds

Fifty grams of Capparis spinosa L. leaves buds were put in thumbles container then it was extracted for 16 hours by using soxhlet apparatus. After that the solvent was removed by using rotary evaporator and the lipids were produced ${ }^{(23)}$.

\section{Separation and characterization of active lipids} isolated from Capparis spinosa $\mathrm{L}$. buds

The different active lipids isolated from Capparis spinosa L. were chemically separated and characterized by using gas chromatography mass spectroscopy (GC-MS) technique depending on GC-MS instrument in Agriculture College at university of Basrah, type Shimadzu GC-MS-QP 2010 Ultra-system has automatic sampler CTC analysis combi PAL robotic arm. The specification of capillary column is Agilent 190915433:1548-52894 HP-SMS. The concentration of $50 \%$ phenyl methyl silox (1/100 v/v in hexane) was used as diluted sample $(2 \mathrm{ml})$ injected ${ }^{(24)}$. The lipids sample was injected in gas chromatography apparatus with standard condition, then different peaks were produced and recorded at various retention times after that the separated active chemical compounds existing in isolated lipids were chemically characterized depending on mass spectra belonging to each separated lipid compound $^{(20)}$.

Estimation and evaluation of antifungal activity of isolated active lipid

Various concentrations belong to isolated active lipids represented by $(0.10,0.15,0.20,0.25$ and 0 , $30 \mathrm{mg} / \mathrm{ml}$ )were prepared and carried out toward growth of three pathogenic fungi which were represented by Aspergillus flavus, Rhizopus and Candida albicans by using well diffusion method in Petri dishes depending on using Sabouraud Dextrose Agar (SAD) and Potato Dextrose Agar PDA as culture media. The concentrations prepared from lipids isolated from Capparis spinosa L. bus were treated with three pathogenic fungi and the Petri dishes were put in the incubator for $24 \mathrm{hr}$ then the inhibition zone diameters were measured ${ }^{(9,25)}$

\section{Results}

Results of active lipids of Capparis spinosa $\mathbf{L}$. buds separated by Gas Chromatography

In this research, the active lipids were isolated from Capparis spinosa L. buds by using continuous extraction depending on hexane as a solvent. The weight of lipids was $1.6 \mathrm{gm}$ and the extraction percentage was $3.2 \%$ as in table (1).

Table (1): Extraction percentage of lipids isolated from Capparis spinosa L. buds.

\begin{tabular}{|l|c|c|c|}
\hline $\begin{array}{l}\text { Active } \\
\text { compounds }\end{array}$ & $\begin{array}{c}\text { Weight of } \\
\text { ground } \\
\text { plant }(\mathrm{gm})\end{array}$ & $\begin{array}{c}\text { Weight of } \\
\text { lipids }(\mathrm{gm})\end{array}$ & $\begin{array}{c}\text { Extraction } \\
\text { percentage } \\
\%\end{array}$ \\
\hline Lipids & 50 & 1.6 & 3.2 \\
\hline
\end{tabular}

The extraction percentage of lipids was calculated from the following equation:

Extraction percentage

This extraction percentage is considered somewhat small compared to another percentage of alkaloid compounds isolated from the same parts of Capparis spinosa L. ${ }^{(20)}$. The isolated active lipids were successfully separated and characterized chemically depending on gas 
chromatography- mass spectroscopy (GC-MS) technique. Figure (1) shows peaks were separated chemically by gas - chromatography analysis where 17 peaks were obtained from this separation process and this indicate presence of 17 lipid chemical compounds.

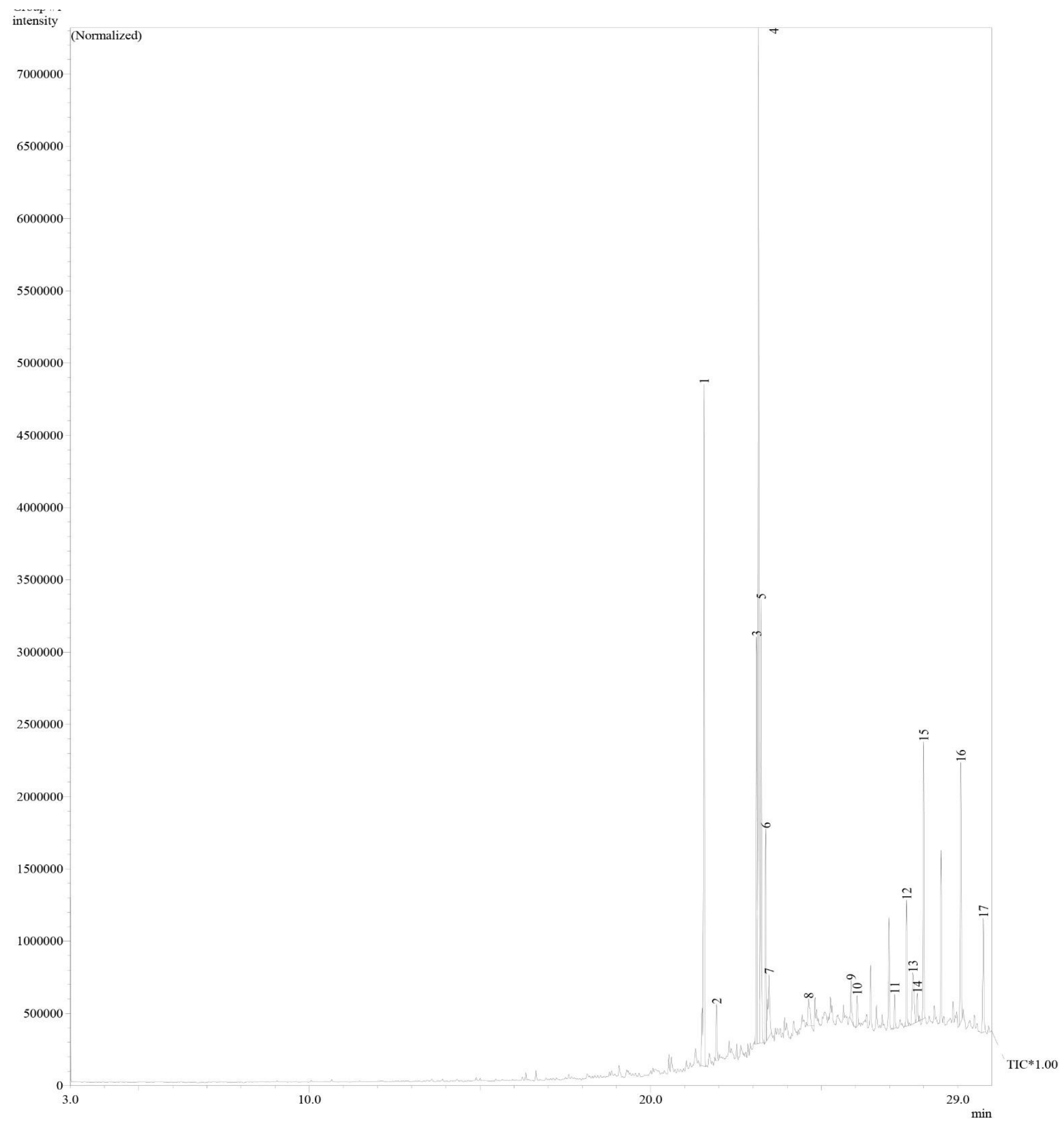

Fig (1): Chromatogram of active lipids of Capparis spinosa L. buds separated by Gas Chromatography (GC) analysis.

The retention times of the peaks $1,2,3,4,5,6,7,8,9,10,11,12,13,14,15,16$ and17 are $21.564,21.932,23.103$, $23.158,23.235,23.373,23.470,24.625,25.872,26.048,27.149,27.499,27.682,27.812,27.996,29.088$ and 29.745 minutes respectively as in the table (2). 
Table (2) Active chemical compounds separated from lipids isolated from Capparis spinosa L. buds by using GC-MS technique.

\begin{tabular}{|c|c|c|c|c|}
\hline \multicolumn{5}{|r|}{ Peak Report TIC } \\
\hline Peak\# & R.Time & Area & Area $\%$ & Name \\
\hline 1 & 21.564 & 10098573 & 18.51 & Hexadecanoic acid, methyl ester \\
\hline 2 & 21.932 & 758295 & 1.39 & 1-(+)-Ascorbic acid 2,6-dihexadecanoate \\
\hline 3 & 23.103 & 5578180 & 10.23 & 9,12-Octadecadienoic acid (Z,Z)-, methyl ester \\
\hline 4 & 23.158 & 13144501 & 24.09 & Methyl 11,14,17-eicosatrienoate \\
\hline 5 & 23.235 & 6050407 & 11.09 & Phytol \\
\hline 6 & 23.373 & 2622309 & 4.81 & Octadecanoic acid, methyl ester \\
\hline 7 & 23.470 & 1646900 & 3.02 & E,E,Z-1,3,12-Nonadecatriene-5,14-diol \\
\hline 8 & 24.625 & 612642 & 1.12 & Eicosane \\
\hline 9 & 25.872 & 575458 & 1.05 & Tetratriacontane \\
\hline 10 & 26.048 & 497409 & 0.91 & Methyl 20-methyl-heneicosanoate \\
\hline 11 & 27.149 & 449929 & 0.82 & Tetracosanoic acid, methyl ester \\
\hline 12 & 27.499 & 1560184 & 2.86 & Hexatriacontane \\
\hline 13 & 27.682 & 1432216 & 2.63 & Oleic acid, eicosyl ester \\
\hline 14 & 27.812 & 417013 & 0.76 & Hexacosane \\
\hline 15 & 27.996 & 3308467 & 6.06 & Hexatriacontane \\
\hline 16 & 29.088 & 3904521 & 7.16 & Hentriacontane \\
\hline 17 & 29.745 & 1896246 & 3.48 & Dotriacontane \\
\hline & & 54553250 & 100.00 & \\
\hline
\end{tabular}

Each separated peak represents one chemical compound therefore these lipidic chemicals were characterized by using mass spectroscopy where each active compound was chemically identified depending on its mass spectrum as in the figure (2).

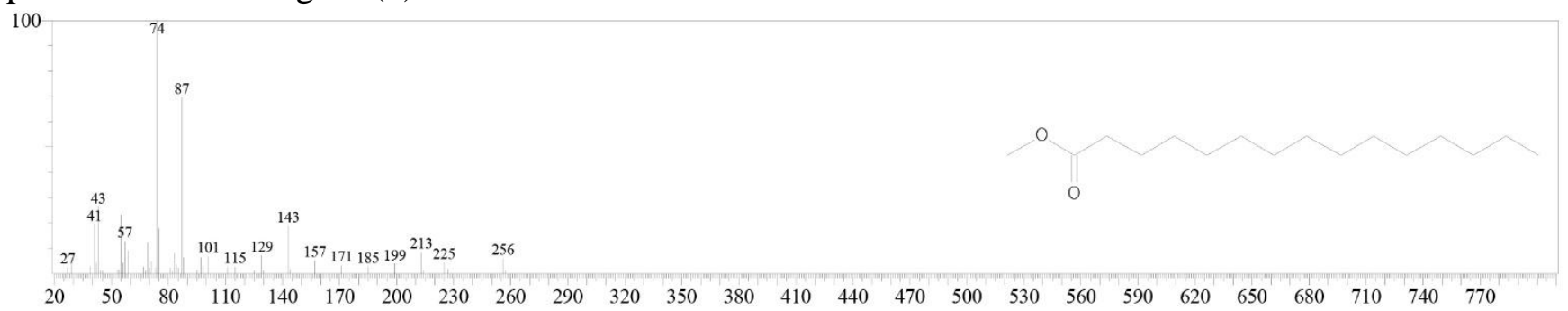

Hexadecanoic acid, methyl ester

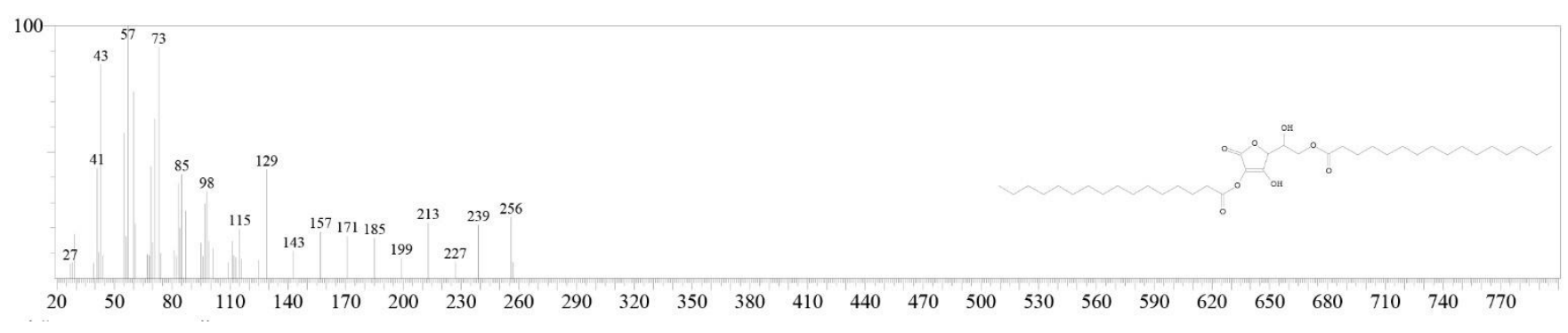

1-(+)-Ascorbic acid 2,6-dihexadecanoate

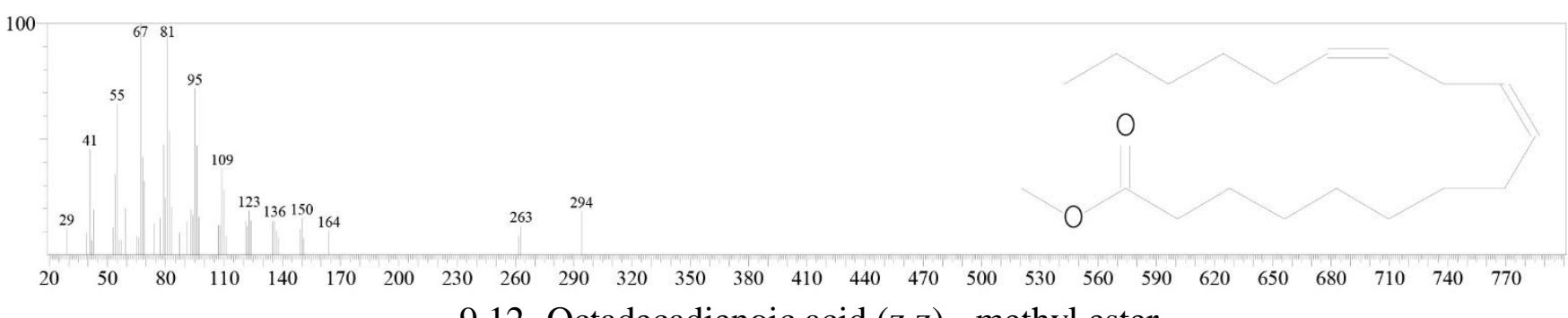

9,12- Octadecadienoic acid (z,z)-, methyl ester 


\section{JMSCR Vol||05||Issue||11||Page 29797-29808||November}
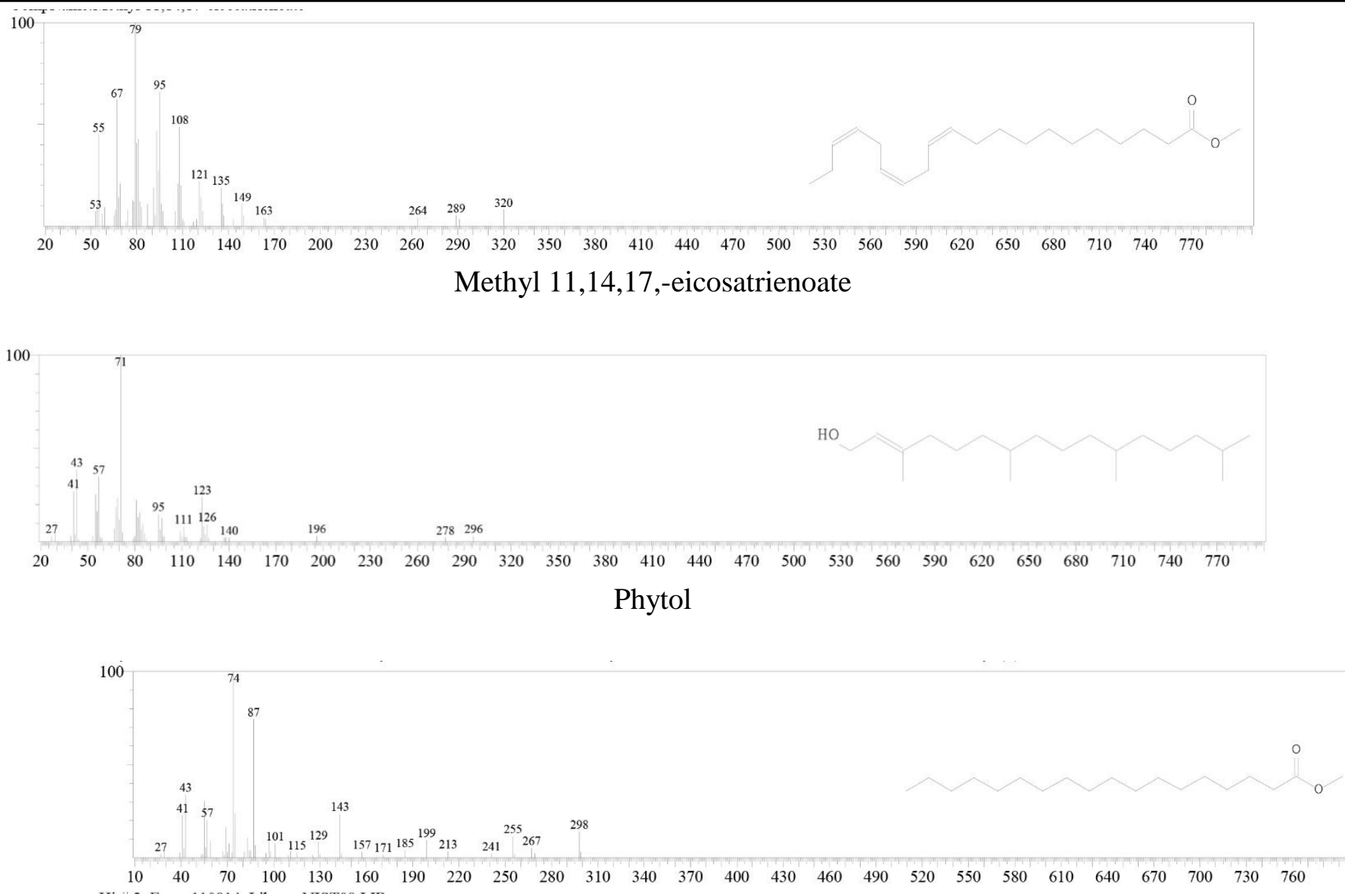

Octodecanoic acid, methyl ester

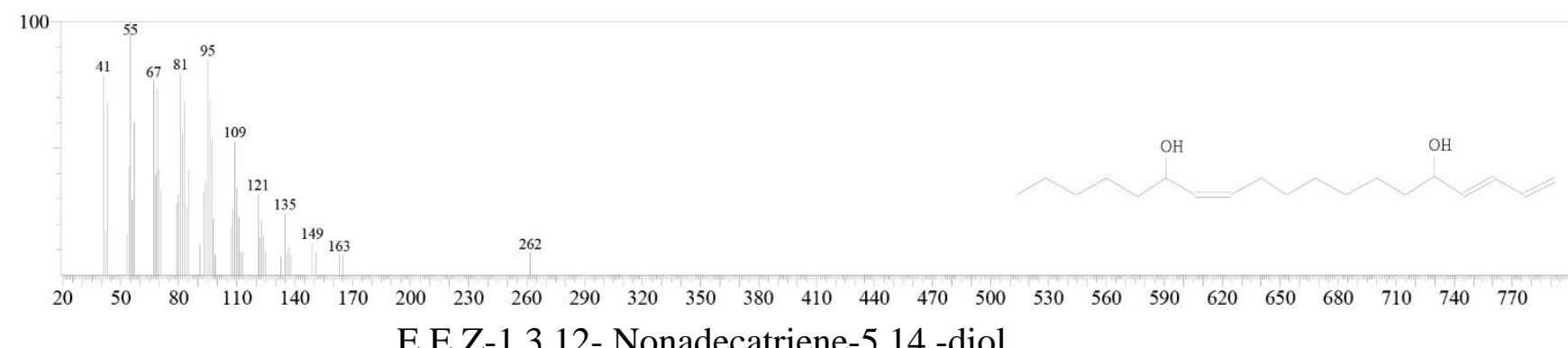

E,E,Z-1,3,12- Nonadecatriene-5,14,-diol.

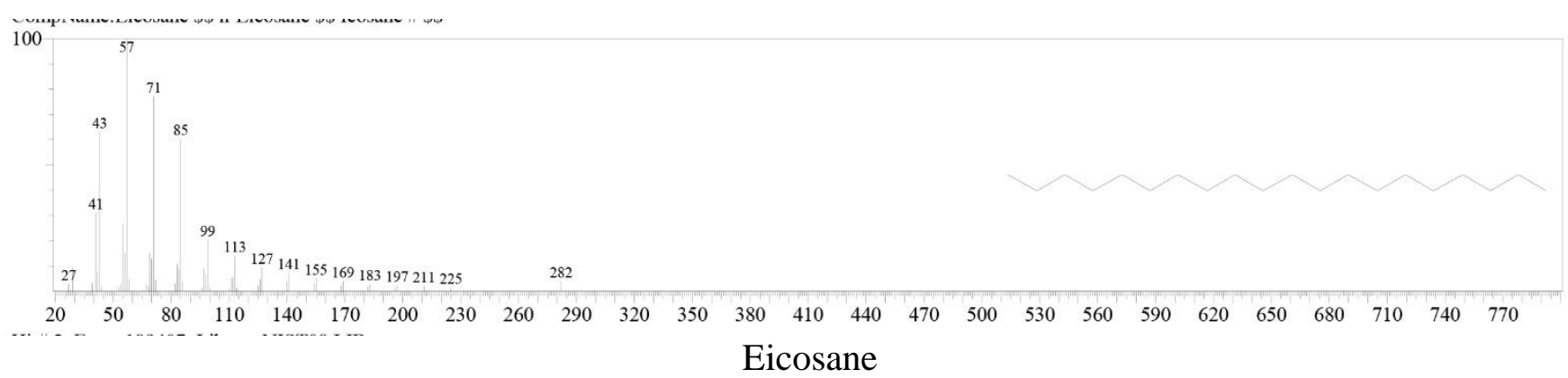




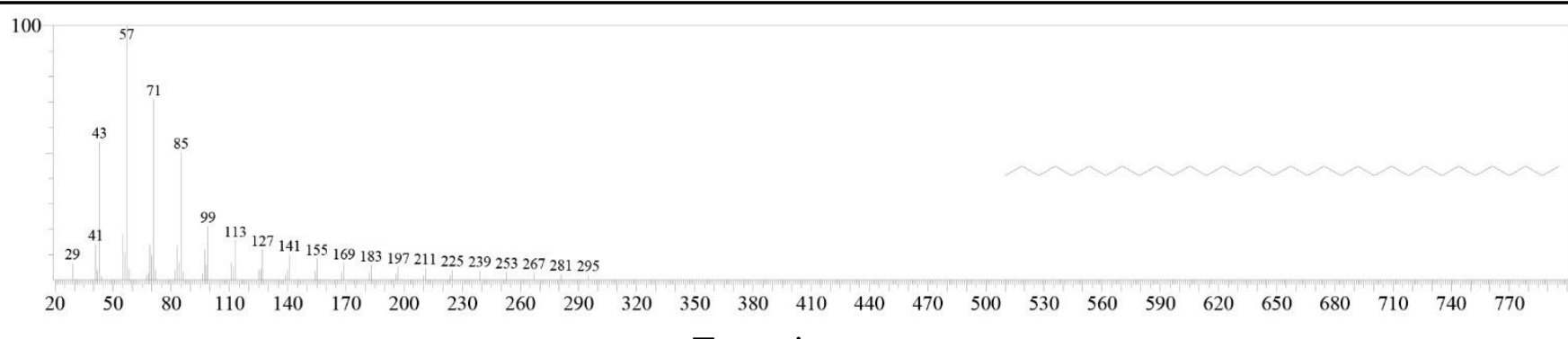

\section{Tetratriacontane}
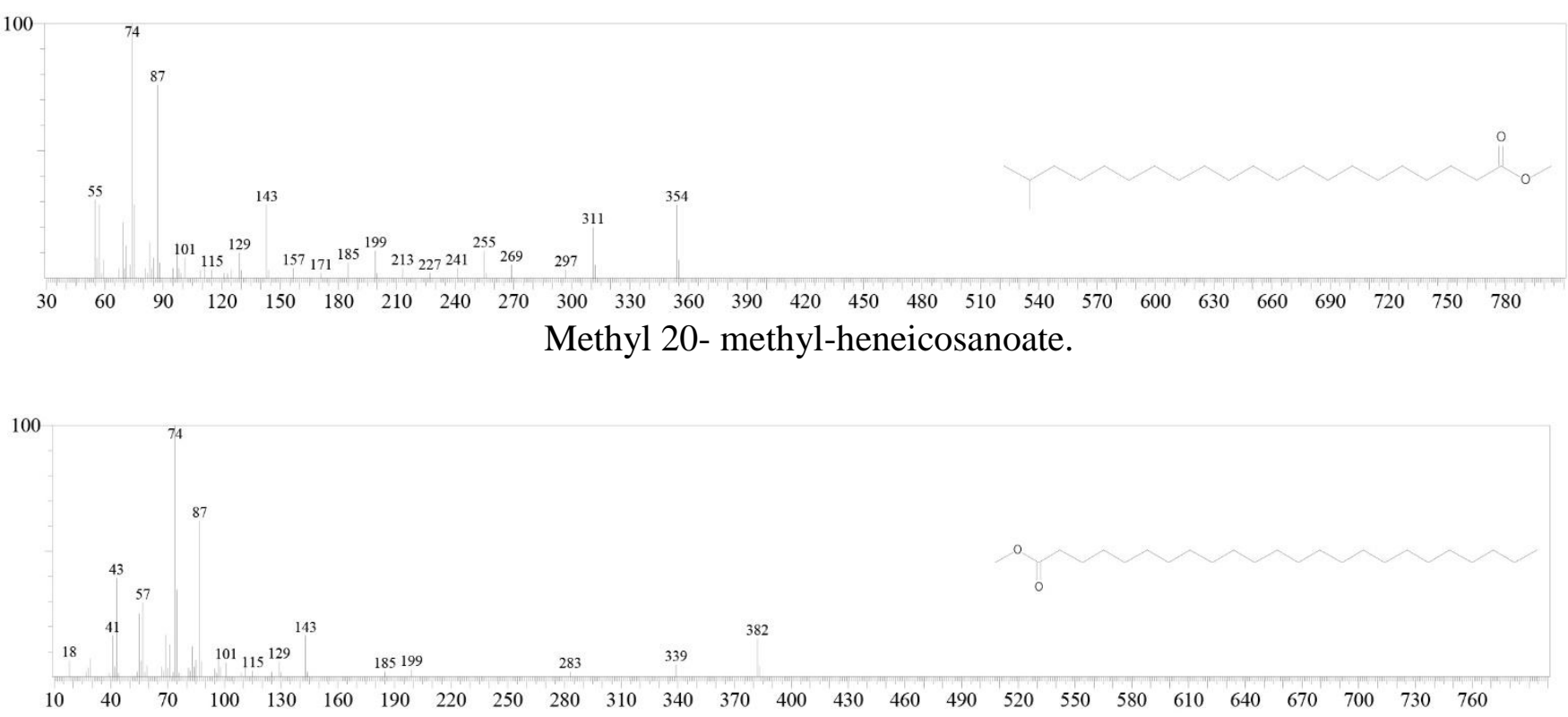

Tetracosanoic acid, methyl ester.

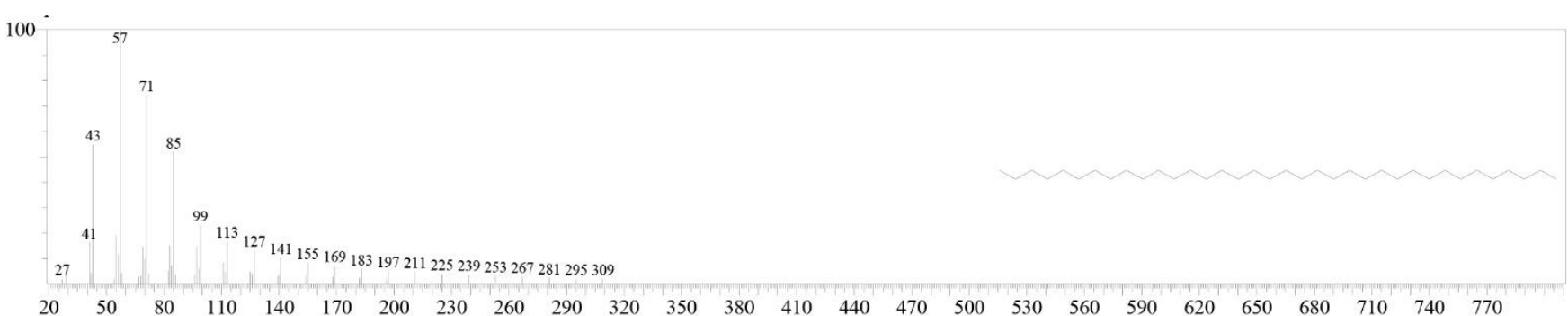

Hexatriacontane.

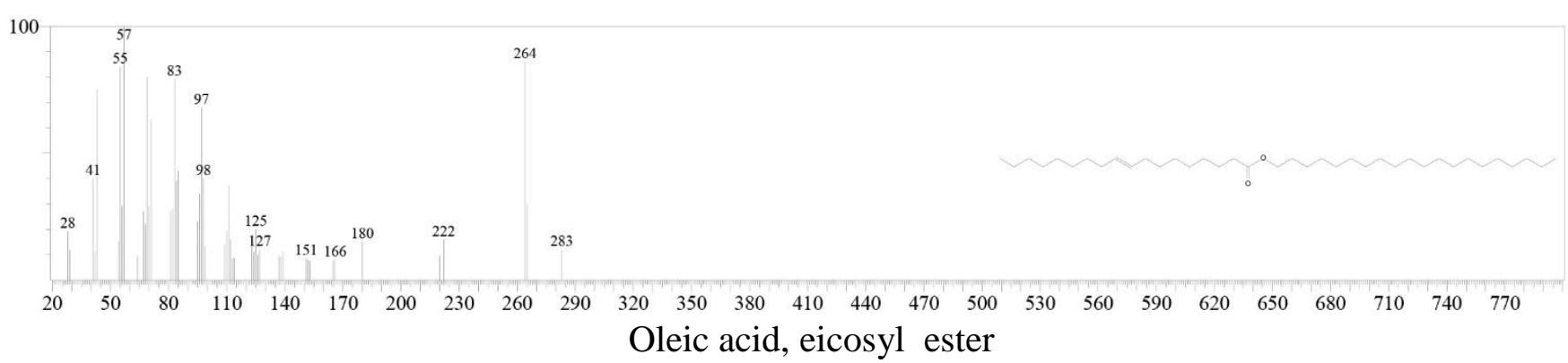




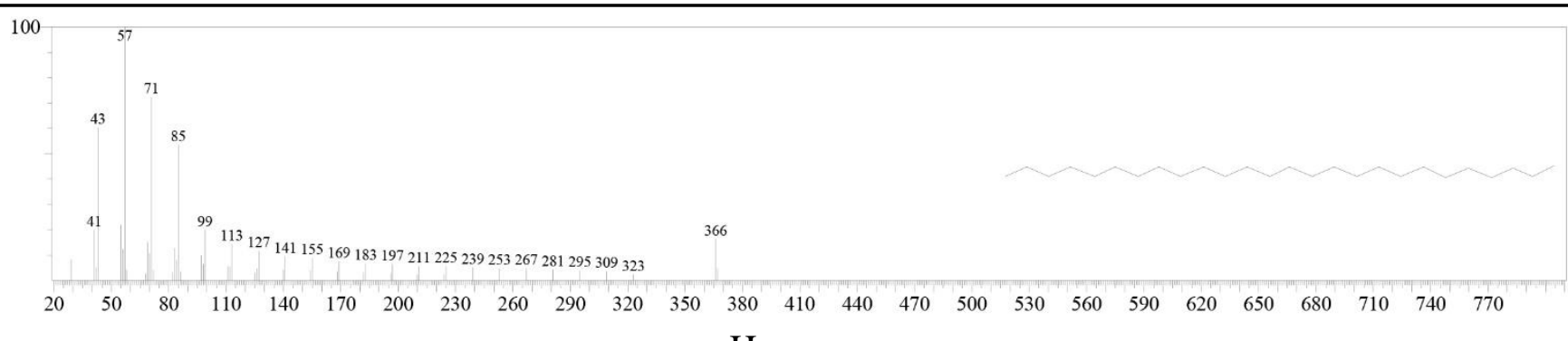

Hexacosane

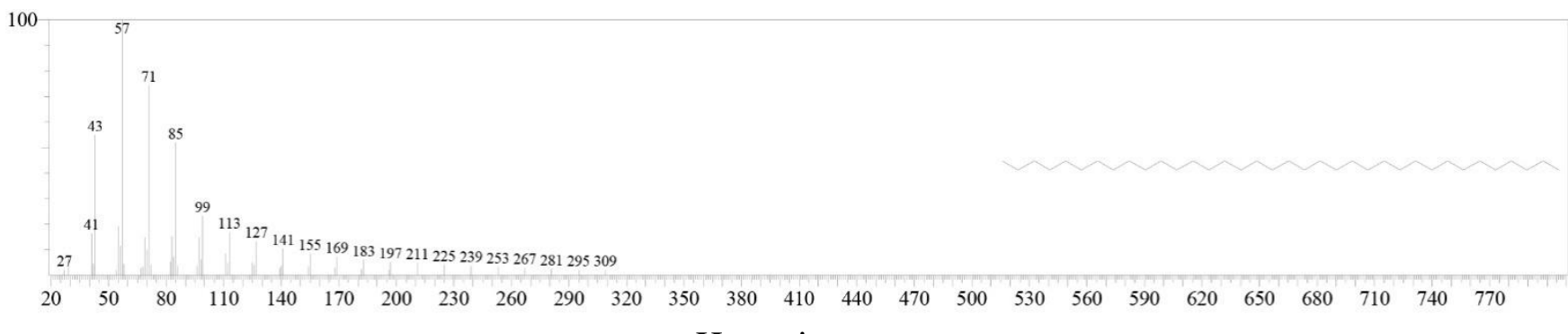

Hexatricontane

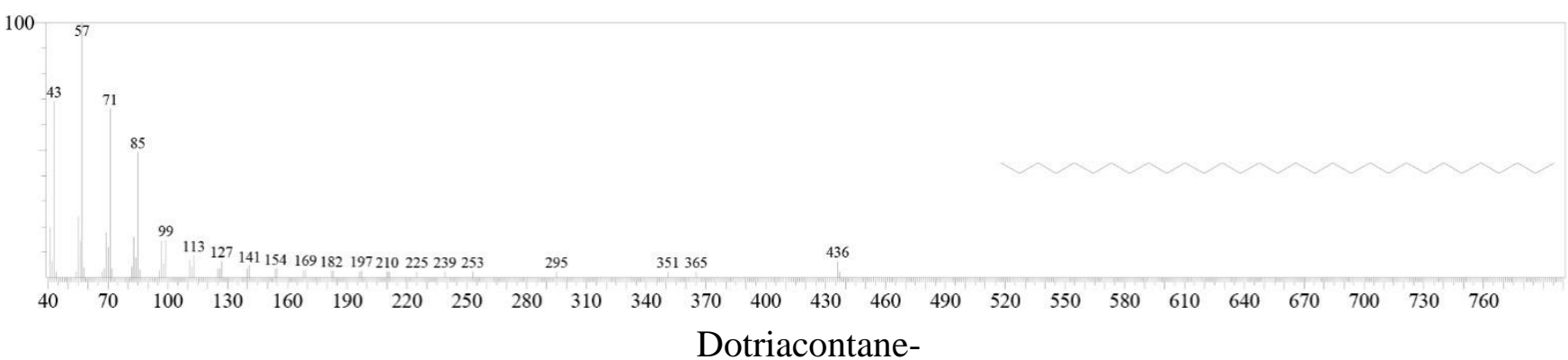

Figure (2): Mass spectra of active chemical compounds separated from lipids of Capparis spinosa L. and characterized by mass spectroscopy.

So, seventeen lipidic active compounds were characterized from GC-MS technique were represented by ,Hexadecanoic acid methyl ester, 1-(+)-Ascorbic acid 2,6-dihexadecanoate, 9,12Octadecadienoic acid (z,z)- methyl ester, Methyl 11,14,17,-eicosatrienoate, Phytol, Octadecanoic acid methyl ester, E,E,Z-1,3,12- Nonadecatriene5,14,-diol, Eicosane, Tetratriacontane, Methyl 20methyl-heneicosanoate, Tetracosanoic acid methyl ester, Hexatriacontane, Oleic acid eicosyl ester, Hexacosane, Hexatricontane, Hentriacontane and Dotriacontane.

Results of antifungal activity of lipids of capparis spinosa $\mathrm{L}$. buds

Different concentrations of active compounds separated and characterized from Capparis spinosa L. buds were carried out against growth of three pathogenic fungi. Table (3) indicates the antifungal activity of mixture of seventeen active lipidic compounds towards Aspergillus flavus, Rhizopus and Candida albicans fungi. The concentrations of $0.10,0.15,0.20,0.25$ and $0.30 \mathrm{mg} / \mathrm{ml}$ recorded inhibition zone diameters equal to $10,17,16,17$ and $17 \mathrm{~mm}$ growth of Aspergillus flavus fungus, but the same concentration against the pathogenic fungus represented by Rhizopus recorded inhibition zone diameters equal to17,16,19,19 and 19mm whereas these concentrations gave antifungal activity against growth of Candida albicans where the inhibition zone diameters were calculated to be $40,37,35,25$ and $25 \mathrm{~mm}$ as in table (3). 
Table (3): Antifungal activity of active lipids isolated from Capparis spinosa L. buds against three pathogenic fungi.

\begin{tabular}{|l|c|c|c|c|}
\hline \multirow{2}{*}{$\begin{array}{l}\text { Active } \\
\text { chemical } \\
\text { compounds }\end{array}$} & Conc.(mg/ml) & \multicolumn{3}{|c|}{ Inhibition zone diameters (mm) } \\
\cline { 2 - 5 } & $\begin{array}{c}\text { Aspergillus } \\
\text { flavus }\end{array}$ & Rhizopus & $\begin{array}{c}\text { Candida } \\
\text { albicans }\end{array}$ \\
\hline \multirow{2}{*}{$\begin{array}{l}\text { mixture of } \\
\text { 17 lipidic } \\
\text { compounds }\end{array}$} & 0.10 & 10 & 17 & 40 \\
\cline { 2 - 5 } & 0.15 & 17 & 16 & 37 \\
\cline { 2 - 5 } & 0.20 & 16 & 19 & 35 \\
\cline { 2 - 5 } & 0.25 & 17 & 19 & 25 \\
\hline
\end{tabular}

\section{Discussion}

Medicinal plants are economic wealth for different societies because they have natural medical value so these plants can treat various diseases and they have no toxic effect. Also the chemical metabolites compounds act with principle of synergistic interaction that lead to achieve the wanted medicinal aim. Capparis spinosa $\mathrm{L}$. is one of many medicinal plants that has therapeutic value because presence of different active chemical compounds in its various parts ${ }^{[26,27,28]}$, the active lipids were isolated from Capparis spinosa L. buds by using continuous extraction depending on hexane as a solvent. The weight of lipids was $1.6 \mathrm{gm}$ and the extraction percentage was $3.2 \%$ as in table (1). This extraction percentage is considered somewhat small compared to another percentage of alkaloid compounds isolated from the same parts of Capparis spinosa L. ${ }^{[20]}$. The most biochemical medicinal studies ensured that the antibacterial, antifungal, anti-parasitic, anticancer and antitumor belongs to abundance of different active secondary metabolites including lipids containing various active chemical classes ${ }^{[24,30]}$. Also in a study, the sterolic lipids of Capparis spinosa L. seeds were isolated and identified by GC-FID analysis and different active sterols were found such as cholesterol, stigmasterol and avenasterol [17]. Also in another study, active alkaloidic compounds were isolated, separated and identified from Capparis spinosa L. buds such piperidine 4ol, 2H-1- benzopyran-2-one and 1- methyl - 2butyl- pyrrolidine ${ }^{[20]}$. Antifungal activity of active lipids isolated from Capparis spinosa L. buds against three pathogenic fungi shown in the table
3 , it is shown that increase of active lipid compounds concentrations led to increase the values of inhibition zone diameters in Aspergillus flavus leading to kill most this pathogenic fungus then increase of biochemical antifungal activity. The increase of antifungal activity of the most active lipid compounds belongs to presence of carboxylic group containing hydroxyl group(-OH) also presence of hydroxyl group alone in the chemical structure of most lipids which are abundant in Capparis spinosa L. buds. The active hydroxyl group has biochemical activity in bonding with hydrogen of proteins of the pathogenic micro-organism and this chemical process leads to break the sulphuric and hydrogen bonds existing in the tertiary structure of proteins in the fungi cells. Different studies indicated the biochemical activity of hydroxyl group against growth of various pathogenic fungi ${ }^{[31,32,7]}$. Concerning Rhizopus fungus, it is noticed that the concentration of active lipid mixture gave a good inhibition zone especially at concentrations of 0.1 , 0.25 and $0.30 \mathrm{mg} / \mathrm{ml}$ but there was somewhat a biological resistance of concentrations of 0.15 and $0.20 \mathrm{mg} / \mathrm{ml}$ where the inhibition zone diameters have nearly decreased. Various studies ensured that active chemical compounds carrying carboxyl and hydroxyl groups have biochemical capability to destruct the membrane and wall of fungi cells and change of the chemical structure of proteins in the fungal cell ${ }^{[33,15]}$. According to antifungal activity of mixture of seventeen lipid compounds isolated from Capparis spinosa L. buds, it was found that the inhibition zone diameters against Candida albicans decreased with increase of lipids concentration and the concentrations of 0.1 $\mathrm{mg} / \mathrm{ml}$ recorded the highest antifungal activity towards this fungus because it gave inhibition zone diameter equal to $40 \mathrm{~mm}$. But the biochemical ability of concentration of $0.15,0.20$ and $0.25 \mathrm{mg} / \mathrm{ml}$ decreased since the inhibition diameters have gradually decreased. The explanation for this case is understood by the high bioresistance of Candida albicans fungus towards these concentrations whereas this resistance of this 
micro-organism has finished at concentration of $0.30 \mathrm{mg} / \mathrm{ml}$ because the inhibition zone diameter value was equal to value which was recorded at concentration $0.25 \mathrm{mg} / \mathrm{ml}$. Also the maximal inhibitory concentration (Max IC) was $0.25 \mathrm{mg} / \mathrm{ml}$ against growth of Aspergillus flavus and Rhizopus but the Max IC of seventeen lipid compounds against Candida albicans is not calculated .Prestudies showed the biochemical medicinal activity of active chemical compounds carrying hydroxyl group against pathogenic fungi because these compounds inhibit the metabolism of nucleic acids represented by deoxyribonucleic acid (DNA) and ribonucleic acid (RNA) since the active hydroxyl group binds chemically with nitrogenous bases which are present in the chemical structure of these nucleic acids. Also carbonyl $\operatorname{group}(\mathrm{C}=\mathrm{O})$ existing in chemical structures of active lipids reacts with these acids $[34,7]$.

\section{Conclusions}

In the current study, the biochemical antifungal activity of active lipids isolated and characterized from Capparis spinosa L. buds showed a very good results for inhibition of growth of the three pathogenic fungi represented by Aspergillus flavus, Rhizopus and Candida albicans. Also the chemical ability of seventeen lipid compounds carrying carbonyl. carboxyl and hydroxyl groups indicated the medicinal importance to use these natural chemical metabolites in treating many various diseases caused by biological disorders of these pathogenic fungi. Furthermore, the biochemical action of the active lipids was explained by the principle of synergistic interaction between these seventeen lipid compounds to achieve the high antifungal activity. Therefore the active lipids isolated from Capparis spinosa L. buds can be used as natural chemical therapies for different diseases caused by these pathogenic micro-organisms.

\section{References}

1. Rodrigues, C. G.; Ferreira, P. R. B.; Mendes, C. S. O.; Junior, R. R.; Valerio, H. M.; Brandi, I. V. and Oliveira, D. A. Antibacterial activity of tamins from Psidium guineense Sw. (Mytaceae). J. Medicinal Plant Res., 8 (35): 1095 - 1100. 2014.

2. Al-Salman, S. J. A.; Abd-Al-MAjeed, M. I.; Al-Ghizawi, G. J. and Al-Maliki, A. D.M. Evaluation of antibacterial and Cytotoxicity activities of 5 - nitro acetyl salicylic acid and 5- bromo acetyl salicylic acid compounds. J. Med. Sic. and Clin. Res., 5 (3): 19578 - 19583. 2017.

3. Nassem, U.; Khurram, Amin, M. U.; Afridi, H. H.; Khan, F. A.; Khayam, M. U.; Saleem, U.; Najeeb, U.; Hussain, J. and Khan, M. A. Comparison of phytochemical constituents and antimicrobial activities of Mentha spicata from four northern district of Khyber Pakhtunkhwa. J. Appl. Parmac. Sci., 1 (7): 72 - 76. 2011.

4. Parekh, J. and Chanda, S. In vitro screening of antimicrobial activity of aqueous and alcoholic extracts of various Indian plant species against selected pathogens from Enterobacteriaceae. Afr. J. Microbial. Res., 1 (6): 92 - 99. 2007.

5. Hudson, E.A; Dinh, P. A.; Kokubun, T.; Simmonds, M. S. J. and Gescher, A. Characterization of potentially chemopreventive phenols in extracts of brown rice that inhibit the growth of human breast and colon cancer cells. J. Cancer Epidemiology, 9: 1163 - 1170. 2000.

6. Padmin, E.; Valarmathi, A. and Rani, U. M. Comparative analysis of chemical composition and antibacterial activities of Mentha spicata and Camellia sinensis. Asian J. Exp. Biol. Sci., 1 (4): 772 - 778. 2010.

7. Al-Maliki, A. D.M. and Badr, S. Q. Isolation and identification of tannins from 
Cuminum cyminum L. seeds and study of their medicinal activity against selective types of pathogenic fungi. J. Missan Res., 8 (16): 147 - 161. 2012.

8. Park, M. J.; Gawk, S. K.; Yang, I.; Chio, W. S.; Jo, H. J.; Chang, J. W.; Jeung, E. B and Choi, I. G. antifungal activity of the essential oils in Syzygium oromaticum (L.). J. Micribiology, 45 (5): 460 - 465. 2007.

9. Cowan, M.M. C. Plant products as antimicrobial agents. Clin. Microb. Rev., 12 (4): 564 - 582. 1997.

10. Webester, J. and Weber, R. W. S. Introduction to fungi. $3^{\text {rd }}$. ed., Cambridge, pp 841. 2007.

11. Hazen, K. C. and Howell, S. A. Candida Cryptococcus and another yeasts of medical importance. In: Manual of clinical microbiology. $9^{\text {th }}$ ed., Washington, D.C. ASM Press, 1762 - 1788.

12. dEnfect, C. and Hube, B. Candida Comparative and functional genomics. Caister Academic Press. 2007. ISBN, 9781904455 3M.

13. Odds, F. C.; Gow, N. A. and Brown, A. J. Toward a molecular understanding of Candida albicans virulence. In: Molecular principles of fungal pathogenesis. Heitman, J.; Filler, S. G.; Edwards, J. E. and Mitchell, A. P., pp $305-319$.

14. Rahnavard, R. and Razavi, N. A review on the medical effects of Capparis spinosa $\mathrm{L}$. Advanced Herbal Medicine., 2 (1): 44 53. 2016.

15. Mahboubi, M. and Mahboubi, A. Antimicrobial activity of Capparis spinosa and its usage in traditional medicine. Herba Polonica., 60 (1): 10 - 24. 2014.

16. Moulia, M.; El-Zhary, Kh.; Elouaddari, A.; Al-Jihad, A.; Jamal Eddine, J.; Seghrouchni, F.; Habti, N. and Badou, A. Capparis spinosa L. promotes antiinflammatory response In vitro through the control of cytokine gene expression in human peripheral blood mononuclear cells. BMC Immunology, 17 (26): 1 - 12. 2016.

17. Tlili, N.; Nasri, N.; Saddaoui, E.; Khaldi, A. and Triki, S. Sterol composition of caper (Capparis spinosa) seeds. Afr. J. Biotechnol., 9 (22): 3328 - 3333. 2010.

18. Jananath, R. Phytochemical and pharmacological screening on roots of $C$. spinosa L. : Capparidaceae. India: Rajiv Ghandi University of Health Sciences, Pub., 2009.

19. Caô, Y. I.; Li, X.; Zheng, M., C. spinosa protects against oxidative stress in systematic sclerosis dermal fibroblast. Arch. Dermatol. Res., 302 (2): 349 - 355. 2010.

20. Abd-Al-Majeed, M. I.; Al-Ghizawi, Gh. J.; Al-Azzawi, B. H. and Al-Maliki, A. D. M. Isolation and identification of alkaloidic extract of Capparis spinosa L. Buds and study of its Cytotoxicity and antibacterial activity. J. Natural Sciences Res., 6 (6): 122 - 130. 2016.

21. Ellis, D. H. Clinical mycology: the human opportunistic mycosis. Gillingham. Printers Pty. Ltd. Australia, (1994). 166pp.

22. McGinnis, M. R. Laboratory Handbook of Medical Mycology. Academic Press, New York, USA. (1980). P: 387 - 390.

23. Harborne, J. Phytochemical methods, $2^{\text {nd }}$ ed., Chapman and Hall, London, UK, 1984.

24. Al-Maliki, A. D. M. and Al-Hilfi, R. S. S. Evaluation of hypoglycemic effect of two flavonoidic compounds isolated from Iraqi Phoenix dactylifera (Gintar) leaflets in alloxan-induced diabetic rabbits. World J. Pharmaceutical. Sci., 5 (7): 61 - 71. 2017.

25. Collee, J.; Fraser, B. and Bimon, A. Practical medical microbiology, Makie and Mc Carteney. $5^{\text {th }}$ ed., Churchill Livingstone, New York, USA. 1996. 
26. Xian-guo, H. and Ursula, M. Antifungal compound from Solanum nigrecens. J. Ethnopharmacology. 43: 173 - 177. 2007.

27. Fragiska, M. wild and cultivated vegetable. Herbs and species in Greek antiquity. Environmental Archacology, 10 (1): 73 82. 2005.

28. Sozzi, G. O.; Vicente, A. R. Capers and Caperberries. Handbook of herbs and spices. Woodhead Pub.., USA. 2006.

29. Lam, S. K. and Ng, T. B. A protein with antiproliferative, antifungal and HIV-1 reverse transcriptase inhibitory activities from caper (C. spinosa L.) seed. Phytomedicine. 16 (5): 444 - 450. 2009.

30. Sokmen, A.; Jones, B. M. and Erturk, M. In vitro antbacterial activity of Turkish medicinal plants. J. Ethnopharmacol., 64: 79 - 86. 1999.

31. Harborne, J. Phytochemical methods. $1^{\text {st }}$ ed. Chapman and Hall, New York, USA. (1974).

32. Hmomoouchi, M.; Elaraki, K.; Tantoui, N. E. and Agoumi, A. Elucidation of antibacterial and antifungal properties of essential oil of Eucalyptus. Plants Mediioinales Etphytothothera, 24: 278 289. 2004.

33. Takashi, T.; Kokuba, R. and Sakaino, M. Antimicrobial activities of Eucalyptus leaf extracts and flavonoids. Let. Appl. Microbiol., 4: 39 - 60. 2004.

34. Rickards, R. W.; Rothschild, J. M.; Willis, A. C.; Chazal. N. M; Kirk, J.; Saliba, K. J. and Smith, G. D. Colothrixine A and B, novel pentacyclic metabolites from calothrix Cyanobacteria with potent activity against Malaria parasites and human cancer cell. Tetrahedron J., 55: 1513 - 1520. 1999. 